\title{
The Role of Bile Acid Sequestrants in the Management of Type 2 Diabetes Mellitus
}

\author{
Om P. Ganda, M.D.
}

\begin{abstract}
The prevalence of type 2 diabetes (T2DM) and cardiovascular disease (CVD) continues to escalate globally. There is now abundant clinical trial evidence that the optimal treatment of CVD risk factors, with lifestyle changes aimed at weight loss in most patients, and pharmacologic management of dyslipidemia and hyperglycemia, can help mitigate the CVD burden. Yet more than 50\% of patients are still not achieving glycosylated hemoglobin $(\mathrm{HbA} 1 \mathrm{c})$ and low-density lipoprotein cholesterol (LDL-C) goals. Over the past 15 years, many novel and emerging drugs have made it possible to achieve optimal glycemic control, generally in combination therapy, without untoward effects of weight gain, hypoglycemia, and other adverse effects with traditional agents. Although the long-term efficacy and safety of some of the newer classes of agents are yet to be determined, bile acid sequestrants represent a unique long-standing class of agents. These drugs have the dual efficacy in glycemic control and LDL-C reduction, and an established record of long-term safety. Colesevelam $\mathrm{HCl}$ is the only drug approved for this dual indication and is an adjunct in the treatment of both hyperglycemia and hypercholesterolemia that frequently co-exist in adults with T2DM.
\end{abstract}

\section{Diabetes and Cardiovascular Disease}

$\mathrm{T}$ HE INCREASED INCIDENCE OF premature coronary heart disease (CHD) continues to present a major challenge in the care of patients with type 2 diabetes (T2DM) across the globe. Although there has been a significant decline in mortality from CHD in the United States due to recently described reductions in other coronary risk factors, these reductions in mortality have been considerably offset by the increasing prevalence of obesity and diabetes. ${ }^{1}$ In a large population study, diabetes was shown to be equivalent to accelerated aging by 15 years, based on the increased rates of premature myocardial infarction (MI). ${ }^{2}$ Moreover, the mortality from cardiovascular disease (CVD) continues to be higher in patients with diabetes following recovery from MI, despite advances in treatment.

In a recent analysis of 11 large studies, encompassing more than 62,000 patients presenting with acute coronary syndromes, of which $10,600(17 \%)$ had known diabetes, the 30 -day and 1-year mortality rates were increased by $40 \%$ and $33 \%$, respectively, in those with diabetes, compared to the rest of the cohorts, after adjustments for other multiple risk factors and covariates. ${ }^{3}$ The precise reasons underlying these differences are not known. However, the lack of early diagnosis of diabetes resulting in a prolonged period of metabolic derangements and suboptimal control of hyperglycemia, hypercholesterolemia, and other risk factors unique to diabetes are likely contributory. In the Nurses' Health Study, the risk of MI or stroke, during 20-year follow-up of 117,000 women, was 2.8-fold greater during the prediabetes phase in those who subsequently developed diabetes. ${ }^{4}$ There is also firm evidence for a markedly increased prevalence of undiagnosed diabetes and prediabetes [impaired fasting glucose (IFG) or impaired glucose tolerance (IGT)] in patients with a recent acute coronary event. In a prospective, 3.2-year follow-up of over 8,000 patients with MI at mean age of 59 and no diabetes at baseline, $62 \%$ were diagnosed with newonset diabetes or prediabetes. ${ }^{5}$ These staggering observations raise the possibility that early diagnosis of hyperglycemia and greater attention to the other risk factors might help reduce the burden of CVD in the population.

\section{Dyslipidemia and CVD in Diabetes}

The dyslipidemia of T2DM and the well-known cardiometabolic syndrome are characterized by a number of interrelated atherogenic abnormalities, including increased levels of triglyceride-rich lipoproteins [very-low-density lipoprotein (VLDL), intermediate-density lipoprotein (IDL), and remnant particles], low levels of high-density lipoprotein

Lipid Clinic, Joslin Diabetes Center and Department of Medicine, Harvard Medical School, Boston, Massachusetts. 
TAble 1. "Legacy Effect" of Improved Glycemic Control With Insulin + Sulfonylurea Therapy

\begin{tabular}{lcc}
\hline & \multicolumn{2}{c}{ Relative risk reduction } \\
\cline { 2 - 3 } Aggregate end point & 1997 & 2007 \\
\hline $\begin{array}{l}\text { Any diabetes-related } \\
\text { end point }\end{array}$ & $12 \%(P=0.029)$ & $9 \%(P=0.040)$ \\
$\begin{array}{l}\text { Microvascular disease } \\
\text { Myocardial infarction }\end{array}$ & $25 \%(P=0.0009)$ & $24 \%(P=0.001)$ \\
All-cause mortality & $6 \%(P=0.052)$ & $15 \%(P=0.014)$ \\
\hline
\end{tabular}

After a median of 8.8 years of posttrial follow-up in the United Kingdom Prospective Diabetes Study (UKPDS).

(HDL), and increased levels of small, dense LDL, as well as non-HDL cholesterol.

Since the mid-1990s, a plethora of randomized, controlled trials with 3-hydroxy-3-methyl-glutaryl-coenzyme A reductase or (HMGCR) inhibitors (statins) have established the efficacy of LDL-lowering agents in reducing cardiovascular outcomes. In a meta-analysis of 16 randomized trials of statin therapy, encompassing 90,056 individuals from various parts of the world, a mean LDL-C reduction of $1 \mathrm{mM}(\sim 40 \mathrm{mg} / \mathrm{dL})$ over 5 years resulted in a $23 \%$ reduction in MI or coronary death $(P<0.0001)$, a $17 \%$ reduction in stroke $(P<0.001)$, and a $12 \%$ reduction in all-cause mortality $(P<0.0001){ }^{6}$ These benefits were seen regardless of the presence or absence of diabetes $(n=18,686)$, or previous CVD, or components of metabolic syndrome (HDL, triglycerides, hypertension), although the absolute risk of events was greater in those with hypertriglyceridemia, low HDL, or hypertension.

A recent meta-analysis included four trials of intensive LDL-lowering therapy in patients with acute coronary syndromes [Pravastatin or Atorvastatin Evaluation and Infection Therapy (PROVE IT) and Aggrastat to Zocor (A to Z)] or stable CAD [Treating to New Targets Study (TNT) and Incremental Decrease in Clinical Endpoints Through Aggressive Lipid Lowering (IDEAL)], involving 27,548 patients. ${ }^{7}$ Of these, 4,379 patients had diabetes. The mean LDL-C achieved by intensive therapy was $75 \mathrm{mg} / \mathrm{dL}$, compared to $101 \mathrm{mg} / \mathrm{dL}$ by standard treatment. This analysis revealed an additional $16 \%$ risk reduction $(\mathrm{RR})$ in coronary death or $\mathrm{MI}(P<0.0003)$ and an $18 \% \mathrm{RR}$ in stroke $(P=0.012)$. Similar outcomes were observed in patients with diabetes. The recent Justification for the Use of Statins in Prevention: An Intervention Trial Evaluating Rosuvastain (JUPITER) primary prevention trial in $\sim 18,000$ nondiabetic patients at high risk due to elevated CRP and features of metabolic syndrome showed a $44 \%$ relative risk reduction in major CVD end points. ${ }^{8}$ Because the absolute baseline risk in patients with diabetes is greater, the benefit in such patients with similar decrease in lipid levels is greater, especially in secondary prevention.

\section{Hyperglycemia and CVD: Implications of Recent Glycemic Control Trials}

There is increasing evidence for the cardiovascular benefits of glycemic lowering, although thus far such evidence has been less strong, compared to LDL lowering. There is epidemiologic evidence of a linear relationship between CVD events and rising glycosylated hemoglobin (HbA1c) levels, starting with glucose levels within the supraphysiologic range, as reflected by $\mathrm{HbA} 1 \mathrm{c}$ levels even below 6\% range., 10 This was most impressive in the recent 14-year prospective analysis of $\sim 12,000$ subjects without diabetes or CVD at baseline. ${ }^{11}$ In this analysis, there was a linear increase in CHD events with a hazard ratio of 1.38 for each $1 \%$ increase in $\mathrm{HbA} 1 \mathrm{c}$, compared to the reference range of $5.0 \%-5.5 \%$. A similar linear relationship with rising $\mathrm{HbA} 1 \mathrm{c}$ levels was reported for the incidence of heart failure in that cohort. ${ }^{11}$ On the other hand, in a recent large database of those with established diabetes for increasing duration, there was suggestion of a U-shaped curve, with best cardiovascular outcomes at levels close to $7.5 \%$, particularly in patients treated with insulin, with or without sulfonylurea and/or metformin. ${ }^{12}$

From the randomized clinical trials, it is apparent that the early intervention leading to better glycemic control results in significantly lower incidence of CV outcomes after many years of observational follow-up of such individuals. This phenomenon has been termed "metabolic memory" or "legacy effect." The first evidence of the salutary effects of glycemic control on CVD outcomes came from the Epidemiology of Diabetes Interventions and Complications (EDIC) study, in a 15-year extended follow-up of Diabetes Control and Complications Trial (DCCT) in type 1 diabetes (T1DM) ${ }^{13}$ In this cohort, a $42 \%-57 \%$ reduction in major CVD events was reported in patients in the original intensive versus standard therapy subgroup (mean $\mathrm{HbA} 1 \mathrm{c}$ at the end of 6.5 years, $7.2 \%$ vs. $9 \%$, respectively). In patients with T2DM studied in the United Kingdom Prospective Diabetes Study (UKPDS), the incidence of MI and total mortality were reduced nonsignificantly at the end of the trial after 10 years, but these outcomes were significantly reduced after another 8 years of follow-up ${ }^{14}$ (Table 1). Similarly, a persistence of cardiovascular benefits was observed, in the smaller subgroup on metformin in the UKPDS.

Table 2. Effects of Intensive Glucose Lowering on Cardiovascular Disease Events in Type 2 Diabetes

\begin{tabular}{lccc}
\hline Parameter & ACCORD $(\mathrm{N}=10,251)$ & ADVANCE $(\mathrm{N}=11,140)$ & VADT $(\mathrm{N}=1,791)$ \\
\hline Mean age & 62 & 66 & 60 \\
Duration of diabetes (years) & 10 & 8 & 11.5 \\
History of cardiovascular disease & $35 \%$ & $32 \%$ & $40 \%$ \\
Body mass index $\left(\mathrm{kg} / \mathrm{m}^{2}\right)$ & 32 & 28 & 31 \\
Baseline HbA1c & $8.3 \%$ & $6.5 \%$ & $9.4 \%$ \\
HbA1c achieved & $6.4 \% \mathrm{vs} .7 .5 \%$ & $0.94(P=0.32)$ & $6.9 \% \mathrm{vs} .8 .4 \%$ \\
Cardiovascular events, hazard ratio & $0.90(P=0.16)$ & 0.93 & $0.88(P=0.12)$ \\
Mortality, hazard ratio & $1.22(P=0.04)$ & 1.07 \\
\hline
\end{tabular}

ACCORD, Action to Control Cardiovascular Risk in Diabetes; ADVANCE, Action in Diabetes and Vascular Disease-Preterax and Diamicron Modified Release Controlled Evaluation; VADT, Veterans Affairs Diabetes Trial; HbA1c, glycosylated hemoglobin. 
Most recently, three large, randomized clinical trials were conducted to compare the effects of intensive glucose lowering with standard glycemic control on CVD outcomes. These studies were the Action to Control Cardiovascular Risk in Diabetes (ACCORD), Action in Diabetes and Vascular Disease-Preterax and Diamicron Modified Release Controlled Evaluation (ADVANCE), and the Veterans Affairs Diabetes Trial (VADT) ${ }^{15-17}$ Table 2 summarizes the salient features of the cohorts and the principal results. There was no decrease in CVD events and mortality in these trials in general. Moreover, in the ACCORD trial, there was an unexpected $22 \%$ increase in total mortality and a $35 \%$ increase in CHD mortality, but a $24 \%$ decrease in nonfatal MI $(P=0.004)$. The etiology of increased mortality in ACCORD remains unexplained, although it was associated with a three-fold increase risk in severe hypoglycemic episodes. Recent studies have documented the increased secretion of epinephrine and release of proinflammatory and prothrombotic cytokines in response to hypoglycemia. ${ }^{18,19}$ This could potentially explain an underlying mechanism for the association of severe hypoglycemia with the increased mortality in ACCORD, although it remains an unproven hypothesis.

It is important to recognize that the three randomized controlled trials (RCTs) summarized above were carried out in relatively older patients, with a mean duration of 8-11.5 years of diabetes, and $32 \%-40 \%$ of patients had preexisting evidence for CVD. Therefore, these were not truly primary prevention trials. In interpreting the disconcerting results from ACCORD, it should be recalled that the subsequent analysis supports the notion that the intensive treatment, per se, was not the reason for the observed increase in mortality. In fact, the excessive mortality in the intensively treated group was seen mainly in those with $\mathrm{HbA} 1 \mathrm{c}$ levels $>7 \%$ or those with difficulty in achieving good glycemic control in the early period of the trial. ${ }^{20}$

The main implication from the ACCORD, ADVANCE, and VADT as well as the other epidemiologic and clinical trial data such as UKPDS is that treatment of hyperglycemia needs to be individualized (Table 3). Intensive glycemic control initiated soon after the diagnosis of diabetes to

Table 3. T2DM and CVD Risk Reduction: LESSONS FROM ADVANCE, ACCORD, VADT, AND UKPDS

Avoid hypoglycemia; severe hypoglycemia associated with mortality, regardless of treatment

Achieve lower glycemic levels earlier to prevent microvascular complications

In early diabetes without advanced CVD, use more extensive glycemic control for modest CVD risk reduction (e.g., target $\mathrm{HbA} 1 \mathrm{c} \leq 6.5 \%$ ?)

Aim to achieve lipid and blood pressure goals; use antiplatelet therapy and promote smoking cessation

Individualize glucose goals for patients with advanced CVD (treat other established cardiovascular risk factors, with more flexible $\mathrm{HbA} 1 \mathrm{c}$ goal)

T2DM, type 2 diabetes; CVD, cardiovascular disease; ADVANCE, Action in Diabetes and Vascular Disease-Preterax and Diamicron Modified Release Controlled Evaluation; ACCORD, Action to Control Cardiovascular Risk in Diabetes; VADT, Veterans Affairs Diabetes Trial; UKPDS, United Kingdom Prospective Diabetes Study; HbA1c, glycosylated hemoglobin. achieve near-normal $\mathrm{HbA} 1 \mathrm{c}$ levels, if achieved safely without recurrent hypoglycemia, is likely to result in the best riskbenefit ratio in reducing CVD outcomes in addition to its known association with microvascular benefits. We also now have several additional medications with much less potential for causing hypoglycemia and weight gain than the ones primarily used in all the clinical trials thus far.

\section{Interventions to Achieve Both LDL and Glycemic Control}

\section{Nonpharmacologic strategies}

Achievement of lipid and glycemic goals in T2DM remain unmet needs. According to recent National Health and $\mathrm{Nu}-$ trition Examination Survey (NHANES) survey, almost 50\% of patients with T2DM are not at the HbA1c goal of $<7 \%$, with similar lack of achievement of cholesterol and blood pressure goals. ${ }^{21}$ On the basis of the clinical trial evidence, the current LDL-C goals were updated by the Adult Treatment Panel III (ATP III) and adopted by the American Diabetes Association (ADA). ${ }^{22}$ These recommendations advocate a minimum goal of LDL-C of $<100 \mathrm{mg} / \mathrm{dL}$ in most patients with T2DM, and a goal of LDL-C $<70 \mathrm{mg} / \mathrm{dL}$ in those with CVD. In addition, it is recommended that treatment strategy should aim to reduce LDL-C by at least $30 \%-$ $40 \%$ from baseline to have a meaningful impact on clinical outcomes.

These goals can rarely be achieved by therapeutic lifestyle interventions alone. Although even modest weight loss is associated with many health benefits, dietary interventions, as recommended, usually result in at best $10 \%-15 \%$ reduction in LDL-C in most patients. ${ }^{22}$ Because most patients with T2DM are overweight or obese, a common myth among many patients and physicians is that weight reduction might cause significant LDL reduction. The fact is that weight reduction, in the absence of specific qualitative dietary changes aimed at lowering cholesterol, rarely results in a significant LDL-C reduction. For example, weight reduction of 5\%-7\% in the intensive lifestyle arm $(n=1,079)$ of the Diabetes Prevention Program (DPP), although very effective in postponing diabetes, resulted in no significant change in total or LDL-C after 3 years, although triglyceride levels were reduced by $15 \%$ and HDL-C increased by a meager $0.25 \%{ }^{23}$ Similarly, in the ongoing LOOK-AHEAD trial in patients with T2DM (Table 4), 2,496 subjects in the Intensive Lifestyle Intervention group (ILI) achieved an impressive mean $8.6 \%$ loss in body weight at 1 year; yet LDL-C declined by only $5.2 \mathrm{mg} \%$, the same as in the control group, ${ }^{24}$ despite significant changes in $\mathrm{HbA1c}$, triglycerides, and HDL-C. Furthermore, in the LOOK-AHEAD trial, there was no difference in the percentage of patients achieving an LDL-C goal of $<100 \mathrm{mg} / \mathrm{dL}$, compared to controls, while there were significant differences in the percentage of patients achieving $\mathrm{HbA} 1 \mathrm{c}$ and blood pressure goals, and there were improvements in physical fitness, C-reactive protein (CRP), and hepatic steatosis. ${ }^{25}$ Clearly, weight reduction is critically important in improving cardiovascular parameters, except for marginal effects on LDL-C.

Finally, even a marked weight loss of up to $25 \%$ of initial body weight achieved by bariatric surgery over 10 years in a large cohort of morbidly obese subjects resulted in no significant change in LDL-C, whereas many other metabolic and 
Table 4. Look AHEAD: Major Benefits of Lifestyle Changes

\begin{tabular}{lccc}
\hline Study goal & Intervention group & Usual care group & P value \\
\hline Weight loss & $8.6 \%$ & $0.7 \%$ & $<0.001$ \\
Increased fitness (after weight adjustment) & $20.9 \%(15.9 \%)$ & $5.8 \%(10.8)$ & $<0.001(<0.001)$ \\
C-reactive protein & $-43.6 \%$ & $-16.7 \%$ & $<0.001$ \\
HbA1c $(<7 \%)$ & $26.4 \%$ & $5.4 \%$ & $<0.001$ \\
Blood pressure $(<130 / 80 \mathrm{mmHg})$ & $15.1 \%$ & $7.0 \%$ & $<0.001$ \\
LDL-C $(<100 \mathrm{mg} / \mathrm{dL})$ & $6.7 \%$ & $8.0 \%$ & 0.340 \\
All three cardiovascular risk factors & $12.8 \%$ & $6.5 \%$ & $<0.001$ \\
\hline
\end{tabular}

Adapted from references 24 and 24a.

AHEAD, Action for Health in Diabetes; HbA1c, glycosylated hemoglobin; LDL-C, low-density lipoprotein cholesterol.

clinical parameters, including glycemic control, improved. ${ }^{26}$ Thus, pharmacological interventions remain the primary mode for achieving success in LDL-lowering strategies.

\section{Pharmacologic strategies}

The statin drugs are currently the drugs of choice for achieving LDL-C reduction; however many patients need up-titration to near-maximal doses to reach currently recommended goals. This is often not carried out and is frequently ineffective because each doubling of statin dose leads to only approximately $5 \%-6 \%$ additional reduction in LDLC. ${ }^{27}$ Another limitation of statins is the significant increase in liver transaminases or myalgia at the high dose of statins as shown in clinical trials and meta-analyses. ${ }^{6,28,29}$ An effective alternative to overcome these limitations of statins is to combine statins with another drug to improve efficacy and safety. The pharmacologic approach best suited to achieve this goal is to combine a statin with a cholesterol absorption inhibitor such as ezetimibe ${ }^{30}$ or a bile acid sequestrant (BAS). ${ }^{31,32}$ BAS were the drugs of choice for LDL reduction in the prestatin era, reducing LDL by up to $20 \%-30 \%$. In a large primary prevention clinical trial, the Lipid Research Clinics Coronary Primary Prevention Trial (LRC-CPPT), a mean 13\% reduction in LDL with cholestyramine was associated with a significant $19 \%$ reduction in CHD death and nonfatal MI ${ }^{33}$ Of much interest was the serendipitous finding in an 8-week, controlled trial in patients with T2DM where cholestyramine, compared to placebo, led to a significant $20 \mathrm{mg} / \mathrm{dL}$ decline in fasting plasma glucose $(P=0.003)$ and a $0.5 \%$ decrease in HbA1c $(P=0.17) .{ }^{34}$ In a short-term observational study with another BAS, colestimide, in Japan, an HbA1c reduction of $0.9 \%$ (from $7.7 \%$ to $6.9 \%$ ) and a $12 \mathrm{mg} / \mathrm{dL}$ reduction in fasting plasma glucose $(P=0.08)$ were reported. ${ }^{35}$ No significant glycemic effects have been reported for the cholesterol absorption inhibitor ezetimibe, which works by a different mechanism via binding to a cholesterol transporter in the intestinal wall. Moreover, there are no long- term studies yet available reagarding the effect of ezetimibe on CVD risk reduction.

\section{The Role of Bile Acid Sequestrants on LDL-C and Glycemic Control}

During the past several years, many new categories of drugs have become available in the management of hyperglycemia in patients with T2DM. Table 5 lists the currently available agents. Metformin is recommended in almost all guidelines as the initial drug for most patients after initial diagnosis, unless contraindicated. ${ }^{36,37}$ If optimal glycemic control is not achieved with monotherapy within several weeks, combination therapy is recommended. The age-old sufonylureas and insulin, while efficacious, have the main limitations of weight gain and hypoglycemia. Thiazolidinediones (TZDs) have the main limitations of weight gain due to lipogenesis, fluid retention, and the known contraindication and "black-box" warning in patients with a history of heart failure. The incretin-based therapies are potentially useful adjuncts, with glucagon-like peptide-1 (GLP-1) analogs leading to some weight loss in many patients; yet neither GLP-1 analogs, or dipeptidyl peptidase-4 (DPP-4) inhibitors have significant lipid benefits. Several novel approaches, such as sodium-glucose transporter-2 (SGLT-2) inhibitors, 11 beta-hydroxysteroid dehydrogenase inhibitor (11-beta-HSD-1 inhibitor), and dual peroxisome proliferatoractivated receptors (PPAR) agonists, are still in clinical trials.

Of the various options for combination therapy in glycemic control, colesevelam hydrochloride $(\mathrm{HCl})$, a BAS available for LDL reduction for more than a decade, was approved by the Food and Drug Administration (FDA) several years ago for glycemic control in adults with T2DM, in combination therapy with other drugs. In the pivotal clinical trials described in detail by Levy in this issue of the journal, its safety and tolerability has been well established, with only a mild-to-moderate increase in side effects, no serious adverse effects, and no increase in rates of hypoglycemia comparable to placebo, and not associated with weight gain. In the same trials, colesevelam $\mathrm{HCl}$ was associated with significant $12 \%$ to $22 \%$ reductions in LDL-C. Earlier studies with colesevelam in patients with hypercholesteremia revealed that the combination of this drug with low-dose statins led to LDL-C reductions in the range achieved by tripling the dose of statin alone. ${ }^{31,32}$

Table 6 summarizes the salient clinical features regarding the efficacy and caveats pertaining to the various agents for the

\section{Table 5. Categories Based on Major Site of Action}

Insulin resistance

Biguanides: metformin

Thiazolidinediones (TZD): pioglitazone, rosiglitazone

Islet-cell dysfunction

Sulfonylureas (SU)/meglitinides

GLP-1 agonists: exenatide, liraglutide

DPP-4 inhibitors: sitaglipitin, saxaglitin

Gastointestinal tract

Alpha-glucosidase inhibitors: acarbose, miglitol

Bile acid sequestrants (BAS): cholestyramine, colesevelam

GLP-1, glucagon-like peptide-1; DPP-4, dipeptidyl peptidase-4. 
Table 6. Salient Features of Drugs for T2DM

\begin{tabular}{lccccc}
\hline Drug & HbAlc reduction & Hypoglycemia & Weight change & Dosing/day & Contraindications/caveat \\
\hline Metformin & $\sim 1-2 \%$ & No & Neutral & 2 & Renal disease \\
Sulfonylureas & $\sim 1-2 \%$ & Yes & Gain & $1-2$ & Renal/liver dosing \\
Repaglinide & $\sim 1.0 \%$ & Yes & Gain & 3 & None \\
Nateglinide & $<1.0 \%$ & Yes & Gain & 3 & None \\
TZDs & $1.0-1.5 \%$ & No & Gain & $1-2$ & CHF \\
GLP-1 agonists & $\sim 1.0 \%$ & No & Loss & $1-2$ injections & Renal dosing (exenatide) \\
DPP-4 inhibitors & $\sim 0.8-1.0 \%$ & No & Neutral & 1 & Renal dosing \\
Pramlintide & $0.5-1.0 \%$ & No & Loss & 3 injections & Gastroparesis \\
AGIs & $\sim 0.5-0.7 \%$ & No & Loss & 3 & Tolerability \\
BAS & $\sim 0.5-0.7 \%$ & No & Neutral & $1-2$ & TG $>500 \mathrm{mg} / \mathrm{dL}$ \\
Insulin & $1-3 \%$ & Yes & Gain & $1-4$ injections & None \\
\hline
\end{tabular}

T2DM, type 2 diabetes mellitus; HbA1c, glycosylated hemoglobin; TZDs, thiazolidinediones; CHF, congestive heart failure; GLP-1, glucagon-like peptide-1; DPP-4, dipeptidyl peptidase-4; AGIs, alpha-glucosidase inhibitors; BAS, bile acid sequestrants; TG, triglycerides.

Table 7. Cardiometabolic Effects of T2DM Drugs

\begin{tabular}{|c|c|c|c|c|c|c|}
\hline $\begin{array}{l}\text { Drug } \\
\text { or changes }\end{array}$ & Hypoglycemia & $\begin{array}{l}\text { Weight } \\
\text { change }\end{array}$ & $\begin{array}{c}L D L-C \text { or } \\
\text { non-HDL-C lowered }\end{array}$ & $\begin{array}{c}\text { Blood pressure } \\
\text { lowered }\end{array}$ & $\begin{array}{l}\text { Inflammation } \\
\text { markers }(C R P) \text { lowered }\end{array}$ & $\begin{array}{l}\text { Cardiovascular } \\
\text { event lowered }\end{array}$ \\
\hline Metformin & No & Neutral & No & No & No & Yes (UKPDS) \\
\hline Sulfonylureas & Yes & + & No & No & No & Yes (UKPDS) \\
\hline TZDs & No & ++ & No & $+/-$ & Yes & Inconclusive \\
\hline GLP-1 agonists & No & Loss & No & $+/-$ & $+/-$ & $?$ \\
\hline DPP-4 inhibitors & No & Neutral & No & $+1-$ & $+/-$ & $?$ \\
\hline AGIs & No & Neutral & No & $+/-$ & $+/-$ & Maybe \\
\hline BAS & No & Neutral & Yes & No & Yes & Yes (LRC-CPPT) \\
\hline Insulin & Yes & + & No & No & No & Yes (UKPDS) \\
\hline Lifestyle changes & No & Loss & Yes & Yes & Yes & Likely (SOS) \\
\hline
\end{tabular}

T2DM, type 2 diabetes mellitus; LDL-C, low-density lipoprotein cholesterol; HDL-C, high-density lipoprotein cholesterol; CRP, C-reactive protein; UKPDS, United Kingdom Prospective Diabetes Study; TZDs, thiazolidinediones; GLP-1, glucagon-like peptide-1; DPP-4, dipeptidyl peptidase-4; AGIs, alpha-glucosidase inhibitors; BAS, bile acid sequestrants; LRC-CPPT, Lipid Research Clinics Coronary Primary Prevention Trial; SOS, Swedish Obesity Study.

glycemic management of T2DM. In the most recent comprehensive meta-analysis, encompassing $>26,000$ patients in 61 clinical trials with oral antidiabetic agents, the mean $\mathrm{HbA} 1 \mathrm{c}$ reductions with most of the agents were in the range of $0.5 \%-1.25 \%{ }^{38}$ Although, BAS were not included in this metaanalysis, the mean $\mathrm{HbA} 1 \mathrm{c}$ reduction with this agent in the range of $0.5 \%-0.7 \%$ is similar to what is seen with various other drugs, as presented in the meta-analysis of colesevelam $\mathrm{HCl}$ trials. ${ }^{39}$

Of particular significance, colesevelam $\mathrm{HCl}$ is the only product approved by the FDA with the dual efficacy in improving $\mathrm{HbA} 1 \mathrm{c}$ and LDL-C in adults with T2DM and primary hyperlipidemia. However, as noted above, in the LRC-CPPT trial, the first-generation BAS cholestyramine was associated with a significantly positive CHD outcome, whereas such an evidence with colesevelam $\mathrm{HCl}$ is still unknown. Colesevelam has also been shown to significantly reduce the inflammatory marker CRP, not seen consistently in trials with several other oral agents, except GLP-1 agonists, the latter perhaps secondary to weight loss. Therefore, combination therapy with colesevelam $\mathrm{HCl}$ is particularly advantageous in adults with T2DM with modestly elevated $\mathrm{HbA1c}$ and LDL-C despite statin therapy.

Table 7 summarizes the data on cardiometabolic effects of the available treatments for T2DM. The evidence for longterm cardiovascular benefits of sulfonylurea and insulin is indirect, from the intensive arm of the UKPDS trial. Also, the evidence for metformin, also from the UKPDS, is based on a relatively small subgroup of less than 350 obese patients. TZDs significantly reduce inflammatory markers, yet the evidence for their cardiovascular benefits remains inconclusive, whereas the risk for heart failure is increased in the presence of left ventricular (LV) dysfunction. In a metaanalysis of studies with acarbose, an alpha-glucosidase inhibitor, the salutary effects on cardiovascular end points are debatable due to relatively small number of subjects. ${ }^{40}$ Evidence for cardiovascular event reduction with cholestyramine, the first-generation BAS, has been reported, whereas colesevelam $\mathrm{HCl}$, the newer agent in this class, has similar clinically relevant effects, including up to $20 \%$ reduction LDL-C reduction and significant reductions in CRP and glycemic control. Finally, lifestyle changes leading to weight reduction are extremely useful in global risk reduction, and the results in the ongoing LOOK-Ahead trial ${ }^{24,25}$ on cardiovascular events and mortality will be of great interest.

\section{Acknowledgments}

Supported, in part, by enrichment core of the DERC grant \# P30 DK-36836.

\section{Author Disclosure Statement}

Dr. Ganda is on the speaker's bureau of Daiichi-Sankyo, Inc. Merck, Takeda, GSK, Abbott, Novo-Nordisk, BMS, and Astra-Zeneca. 


\section{References}

1. Ford ES, Ajani UA, Croft JB, Critchley JA, Labarthe DR, Kottke TE, Giles, Capewell S. Explaining the decrease in U.S. deaths from coronary disease, 1980-2000. N Engl J Med 2007;356:2388-2398.

2. Booth GL, Kapral MK, Fung K, Tu JV. Relation between age and cardiovascular disease in men and women with diabetes compared with non-diabetic people: A population-based retrospective cohort study. Lancet 2006;368:29-36.

3. Donahoe SM, Stewart GC, McCabe CH, Mohanavelu S, Murphy SA, Cannon CP, Antman EM. Diabetes and mortality following acute coronary syndromes. JAMA 2007;298: 765-775.

4. Hu FB, Stampfer MJ, Haffner SM, Solomon CG, Willett WC, Manson JE. Elevated risk of cardiovascular disease prior to clinical diagnosis of type 2 diabetes. Diabetes Care 2002;25: 1129-1134.

5. Mozaffarian D, Marfisi R, Levantesi G, Silletta MG, Tavazzi L, Tognoni G, Valagussa F, Marchiali R. Incidence of newonset diabetes and impaired fasting glucose in patients with recent myocardial infarction and the effect of clinical and lifestyle risk factors. Lancet 2007;370:667-675.

6. Cholesterol Treatment Trialists' (CTT) Collaborators. Efficacy of cholesterol-lowering therapy in 18,686 people with diabetes in 14 randomised trials of statins: A meta-analysis. Lancet 2008;371:117-125.

7. Cannon CP, Steinberg BA, Murphy SA, Mega JL, Braunwald E. Meta-analysis of cardiovascular outcomes trials comparing intensive versus moderate statin therapy. I Am Coll Cardiol 2006;48:438-445.

8. Ridker PM, Danielson E, Fonseca FA, Genest J, Gotto AM, Kastelein JJP, Koenig W, Libby P, Lorenzatti AJ, MacFadyen JG, Nordestgaard BG, Shepherd J, Willerson JT, Glynn RJ; JUPITER Study Group. Rosuvastatin to prevent vascular events in men and women with elevated C-reactive protein. N Engl J Med. 2008;359:2195-2207.

9. Effect of intensive blood-glucose control with metformin on complications in overweight patients with type 2 diabetes (UKPDS 34). UK Prospective Diabetes Study (UKPDS) Group. Lancet 1998;352:854-865.

10. Selvin E, Marinopoulos S, Berkenblit G, Rami T, Brancati FL, Powe NR, Golden SH. Meta-analysis: Glycosylated hemoglobin and cardiovascular disease in diabetes mellitus. Ann Intern Med 2004;141:421-431.

11. Matsushita K, Blecker S, Pazin-Filho A, Bertoni A, Chang PP, Coresh J, Selvin E. The Association of hemoglobin A1c with incident heart failure among people without diabetes: The Atherosclerosis Risk in Communities (ARIC) Study. Diabetes 2010;59:2020-2026.

12. Currie CJ, Peters JR, Tynan A, Evans M, Heine RJ, Bracco OL, Zagar T, Poole C. Survival as a function of HbA1c in people with type 2 diabetes: a retrospective cohort study. The Lancet 2010;375:481-489.

13. Nathan DM, Cleary PA, Backlund JY, Genuth SM, Lachin JM, Orchard TJ, Raskin P, Zinman B. Intensive diabetes treatment and cardiovascular disease in patients with type 1 diabetes. N Engl J Med 2005;353:2643-2653.

14. Holman RR, Paul SK, Bethel MA, Matthews DDR, Neil HAW. 10-Year follow-up of intensive glucose control in type 2 diabetes. N Engl J Med 2008;359:1577-1589.

15. Action to Control Cardiovascular Risk in Diabetes Study Group, Gerstein HC, Miller ME, Byington RP, Goff DC Jr, Bigger JT, Buse JB, Cushman WC, Genuth S, Ismail-Beigi F, Grimm RH, Probstfield JL, Simons-Morton DG, Friedewald
WT. Effects of intensive glucose lowering in type 2 diabetes. N Engl J Med 2008;358:2545-2559.

16. ADVANCE Collaborative Group, Patel A, MacMahon S, Chalmers J, Neal B, Billot L, Woodward M, Marre M, Cooper M, Glasziou P, Grobbee D, Hamet P, Harrap S, Liu LS, Mancia G, Mogensen CE, Pan CY, Poulter N, Rodgers A, Williams B, Bompoint S, de Galan BE, Joshi R, Travert F, Fassett R. Intensive blood glucose control and vascular outcomes in patients with type 2 diabetes. $N$ Engl J Med 2008;358:2560-2572.

17. Duckworth W, Abraira C, Moritz T, Reda D, Emanuele N, Reaven PD, Zieve FJ, Marks J, Davis SN, Hayward R, Warren SR, Goldman S, McCarren M, Vitek ME, Henderson WG, Huang GD; VADT Investigators. Glucose control and vascular complications in veterans with type 2 diabetes. $N$ Engl J Med 2009;360:129-139.

18. Gogitidze JN, Hedrington MS, Briscoe VJ, Tate DB, Ertl AC, Davis SN. Effects of acute hypoglycemia on inflammatory and pro-atherothrombotic biomarkers in individuals with type 1 diabetes and healthy individuals. Diabetes Care 2010; 33:1529-1535.

19. Wright RN, Newby DE, Stirling D, Ludlam CA, Macdonald IA, Frier BM. Effects of acute insulin-induced hypoglycemia on indices of inflammation: putative mechanism for aggravating vascular disease in diabetes. Diabetes Care 2010;33: 1591-1597.

20. Riddle MC, Ambrosius WT, Brillon DJ, Buse JB, Byington RP, Cohen RM, Goff DC Jr, Malozowski S, Margolis KL, Probstfield JL, Schnall A, Seaquist ER, and for the Action to Control Cardiovascular Risk in Diabetes Investigators. Epidemiologic relationships between $\mathrm{A} 1 \mathrm{C}$ and all-cause mortality during a median 3.4-year follow-up of glycemic treatment in the ACCORD trial. Diabetes Care 2010;33:983-990.

21. Cheung BM, Ong KL, Cherny SS, Sham PC, Tso AW, Lam KS. Diabetes prevalence and therapeutic target achievement in the United States,1999 to 2006. Am J Med. 2009;122:443-453.

22. Standards of medical care in diabetes-2010. Diabetes Care 2010; 33(Suppl 1):S11-S61.

23. Ratner R, Goldberg R, Haffner S, Marcovina S, Orchard T, Fowler S, Temprosa M; Diabetes Prevention Program Research Group. Impact of intensive lifestyle and metformin therapy on cardiovascular disease risk factors in the diabetes prevention program. Diabetes Care 2005;28:888-894.

24. Pi-Sunyer X, Blackburn G, Brancati FL, Bray GA, Bright R, Clark JM et al. Reduction in weight and cardiovascular disease risk factors in individuals with type 2 diabetes: Oneyear results of the look AHEAD trial. Diabetes Care 2007;30: 1374-1383.

24a.Belalcazar LM, Reboussin DM, Haffner SM, Hoogeveen RC, et al. A one-year lifestyle intervention for weight loss in persons with type 2 diabetes reduces high c-reactive protein levels and identifies metabolic predictors of change, from the Look AHEAD (Action for Health in Diabetes) Study. Diabetes Care 2010 [Epub ahead of print; 10.2337/ dc10-0728].

25. Lazo M, Solga SF, Horska A, Bonekamp S, Diehl S, Brancati FL, Wagenknecht LE, Pi-Sunyer FX, Kahn SE, Clark JM; for the Fatty Liver Subgroup of the Look AHEAD Research Group. The effect of a 12-month Intensive lifestyle intervention on hepatic steatosis in adults with type 2 diabetes. Diabetes Care Epub of print July 27, 2010, doi:10.2337/dc10-0856.

26. Sjostrom L, Narbro K, Sjostrom CD, Karason K, Larsson B, Wedel H, Lystig T, Sullivan M, Bouchard C, Carlsson B, Bengtsson C, Dahlgren S, Gummesson A, Jacobson P, Karlsson J, Lindroos AK, Lonroth AK, Naslund I, Olbers T, 
Stenlof K, Torgerson J, Agren G, Carlsson LM; Swedis Obese Subjects Study. Effects of bariatric surgery on mortality in Swedish obese subjects. N Engl J Med 2007;357:741-752.

27. Illingworth DR. An overview of lipid-lowering drugs. Drugs 1988;36(Suppl 3):63-71.

28. Alsheikh-Ali AA, Maddukuri PV, Han H, Karas RH. Effect of the magnitude of lipid lowering on risk of elevated liver enzymes, rhabdomyolysis, and cancer: Insights from large randomized statin trials. J Am Coll Cardiol 2007;50:409-418.

29. Armitage J. The safety of statins in clinical practice. Lancet 2007;370:1781-1790.

30. Gagne C, Bays HE, Weiss SR, Mata P, Quinto K, Melino M, Cho M, Musliner TA, Gumbiner B. Efficacy and safety of ezetimibe added to ongoing statin therapy for treatment of patients with primary hypercholesterolemia. Am J Cardiol 2002;90:1084-1091.

31. Knapp HH, Schrott H, Ma P, Knopp R, Chin B, Gaziano JM, Donovan JM, Burke SK, Davidson MH. Efficacy and safety of combination simvastatin and colesevelam in patients with primary hypercholesterolemia. Am J Med 2001;110:352-360.

32. Insull W, Jr. Clinical utility of bile acid sequestrants in the treatment of dyslipidemia: A scientific review. South Med J 2006;99:257-273.

33. The Lipid Research Clinics Coronary Primary Prevention Trial results. II. The relationship of reduction in incidence of coronary heart disease to cholesterol lowering. JAMA 1984; 251:365-374.

34. Garg A, Grundy SM. Cholestyramine therapy for dyslipidemia in non-insulin-dependent diabetes mellitus. A short-term, double-blind, crossover trial. Ann Intern Med 1994;121:416-422.

35. Kobayashi M, Ikegami H, Fujisawa T, Nojima K, Kawabata Y, Noso S, Noso S, Babaya N, Itoi-Babaya M, Yamaji K, Hiromine $Y$, Shibata M, Ogihara T. Prevention and treatment of obesity, insulin resistance, and diabetes by bile acidbinding resin. Diabetes 2007;56:239-247.
36. Nathan DM, Buse JB, Davidson MB. Medical management of hyperglycemia in type 2 diabetes: a consensus algorithm for the initiation and adjustment of therapy. A consensus statement of the American Diabetes Association and the European Association for the Study of Diabetes. Diabetes Care. 2009;32:193-203.

37. Rodbard H, Jellinger P, Davidson JA, Einhorn D, Garber AJ, Grunberger G, Handelsman Y, Horton ES, Lebovitz H, Levy P, Moghissi ES, Schwartz SS. Statement by an American Association of Clinical Endocrinologists/American College of Endocrinology consensus panel on type 2 diabetes mellitus: An algorithm for glycemic control. Endocr Pract 2009;15: 540-559.

38. Sherifali D, Nerenberg K, Pullenayegum E, Cheng JE, Gerstein HC. The effect of oral antidiabetic agents on A1C levels. Diabetes Care 2010;33:1859-1864.

39. Jialal I, Abby SL, Misir S, Nagendran S. Concomitant reduction in low-density lipoprotein cholesterol and glycated hemoglobin with colesevelam hydrochloride in patients with type 2 diabetes: A pooled analysis. Metab Syndr Relat Disord 2009;7:255-258.

40. Hanefeld M, Cagatay M, Petrowitsch T, Neuser D, Petzinna D, Rupp M. Acarbose reduces the risk for myocardial infarction in type 2 diabetic patients: meta-analysis of seven long-term studies. Eur Heart J 2004;25:10-16.

Address correspondence to: Om P. Ganda, M.D. Lipid Clinic Joslin Diabetes Center and Department of Medicine Harvard Medical School Boston, MA 02115

E-mail: om.ganda@joslin.harvard.edu 
